\title{
Los caminos de la utopía: enfoques y perspectivas del campo de la economía social
}

Paula Cecilia Rosa*

Doctora en Ciencias Sociales. Miembro del equipo de docencia e investigación del Programa Integral de Economía Social y Solidaria, Universidad Nacional de San Martín, Buenos Aires, Argentina. Correo electrónico: paula_rosa00@yahoo.com.ar

Recibido: 10 de noviembre del 2015

Aceptado: 31 de mayo del 2016

Cómo citar este artículo: Rosa, P. C. (2016). Los caminos de la utopía: enfoques y perspectivas del campo de la economía social. Cooperativismo \& Desarrollo, 24(109), XX-xx. doi: 10.16925/co.v24i109.1512

\section{Resumen}

Propósito: este artículo pretende ser una introducción al estudio de la economía social brindando un primer acercamiento a las principales corrientes, debates y enfoques presentes en diversos estudios desarrollados en esta área. Temas: se parte de una caracterización sintética de las corrientes de pensamiento que le dieron origen a la economía social, las particularidades de los sujetos sociales que la conforman y los contrastes encontrados en diferentes contextos territoriales. Asimismo, se analizan sus transformaciones en relación con la "cuestión social" para llegar a su situación actual. Desarrollo: en este artículo se presentarán los principales debates desde la categoría analítica de campo. Esta fue construida para hacer referencia a la economía social como una rama de conocimiento específico que posee su propio objeto de estudio, su corpus teórico y una metodología de investigación particular, pero también es concebida como una realidad social y política compleja que está constituida por experiencias, prácticas y actores de diferente tipo (Estado, productores, organizaciones, cooperativas, entre otros). Conclusiones: la denominación de campo es utilizada, y definida, en este artículo para dar cuenta de la complejidad de la economía social a partir de la diversidad de modalidades que puede asumir.

Palabras clave: cuestión social, economía social, neoliberalismo, socialistas utópicos. 


\title{
The paths of utopia: approaches and perspectives from the field of social economy
}

\begin{abstract}
Purpose: This article is an introduction to the study of the social economy, providing a first approach to the main schools of thought, debates, and approaches found in various studies conducted in this area. Topics: It begins with a synthetic characterization of the schools of thought that gave rise to the social economy, the particularities of the social subjects that compose it, and the contrasts found in different territorial contexts. Moreover, its transformations are discussed in relation to the "social question" in order to arrive at its current situation. Development: In this article, the main discussions will be presented from the analytical category of field. This was constructed to refer to the social economy as a branch of specific knowledge that has its own object of study, theoretical corpus, and particular research methodology; however, it is also conceived as a complex social and political reality consisting of experiences, practices, and actors of different types (State, producers, organizations, cooperatives, etc.). Conclusions: The term field is used and defined in this article to account for the complexity of the social economy based on the variety of forms it can take.
\end{abstract}

Keywords: social question, social economy, neoliberalism, utopian socialists

\section{Os caminhos da utopia: enfoques e perspectivas do campo da economia social}

\section{Resumo}

Propósito: este artigo pretende ser uma introdução ao estudo da economia social apresentando uma primeira aproximação às principais correntes, debates e enfoques presentes em diversos estudos desenvolvidos nessa área. Temas: parte-se de uma caracterização sintética das correntes de pensamento que lhe deram origem à economia social, às particularidades dos sujeitos sociais que a conformam e aos contrastes encontrados em diferentes contextos territoriais. Dessa forma, analisam-se suas transformações com relação à "questão social" para chegar a sua situação atual. Desenvolvimento: neste artigo serão apresentados os principais debates desde a categoria analítica de campo. Esta foi construída para fazer referência à economia social como um ramo de conhecimento específico que possui seu próprio objeto de estudo, seu corpus teórico e uma metodologia de pesquisa particular, mas também é concebida como uma realidade social e política complexa que está constituída por experiências, práticas e atores de diferente tipo (Estado, produtores, organizações, cooperativas, entre outros). Conclusões: a denominação de campo é utilizada, e definida, neste artigo para dar conta da complexidade da economia social a partir da diversidade de modalidades que pode assumir.

Palavras-chave: questão social, economia social, neoliberalismo, socialistas utópicos. 


\section{Introducción}

Cuando se inicia la lectura de artículos y libros dedicados a la economía social es frecuente encontrar puntos de partida compartidos por los diferentes autores. Se podría decir que el primero de ellos es el que sostiene que el concepto de economía social es polisémico. De este modo, se comprende desde el inicio que este es un campo complejo, es decir, que no es posible hallar una definición unificada a la cual recurrir como una especie de "salvavidas teórico". Por el contrario, es pertinente iniciar el acercamiento al campo a partir de la lectura y revisión de autores y definiciones para "elegir" una postura propia - o la de los autores reconocidos con los que se coincide- en relación con lo que significa la economía social. Asimismo, se debe definir un modo de enunciar a esta área, así que se reconoce que existen diferentes formas de nombrarla según la postura que se ha elegido previamente. Entre las denominaciones más utilizadas se pueden hallar: economía solidaria, de la solidaridad, popular, social, comunitaria, del trabajo, de la vida, entre otras. Cada una posee sus especificaciones y sus usos particulares. Es posible afirmar, siguiendo lo planteado por diferentes autores y referentes, que este es un campo de estudio que se encuentra en proceso de construcción conceptual (Hintze, 2010; Caracciolo y Foti, 2012).

A las diversidades en cuanto al significado y denominación, se puede añadir que este campo se presta para diversos abordajes posibles. Esto significa que puede ser estudiado de forma teórica, a partir del análisis de políticas públicas o programas específicos del sector, realizando comparaciones tanto a nivel nacional como internacional; y también a través del estudio de experiencias empíricas, de las prácticas sociales, económicas y productivas de los actores (productores, cooperativas, organizaciones, etcétera). De este modo, bucear por esta área implica un encuentro con infinidad de perspectivas de estudio tanto general por ejemplo, análisis de las estructuras económicas financieras actuales - como específico - a partir del estudio, por ejemplo, de las vivencias y sentidos dados al accionar de un grupo de productores rurales. Parte de la diversidad está dada porque este campo está compuesto por entidades heterogéneas (cooperativas grandes y pequeñas, organizaciones sociales, emprendimientos familiares, etcétera) que varían significativamente en sus metas, accionar, miembros y propuestas. Desde este punto de vista, el campo puede combinar diferentes disciplinas para su estudio y abordaje. Existen análisis hechos por la agronomía, la economía, la antropología y la sociología. Cada una le da su propia impronta, que puede ser más técnica, social o política, dependiendo del objetivo planteado.

A esta diversidad también se suma el hecho de que la economía social varía según el contexto territorial en el cual se desarrolle (Rincón-Gamba, 2012). De este modo, se pueden observar diferencias entre, por ejemplo, la perspectiva latinoamericana, la europea y la canadiense (Mutuberría Lazarini, 2008; Chaves, 1997). Por ello, la Economía Social debe comprenderse en cada contexto institucional, territorial e histórico particular (Chaves, 1997). Estas diferencias, en términos espaciales, son acompañadas por diferencias temporales. Estas últimas tienen que ver con que el campo de la economía social ha sufrido transformaciones desde su origen. Es decir, que, al realizar un "rastrillaje" a lo largo del tiempo, se evidencia que ella ha variado como corriente de pensamiento, pero también como práctica.

Este artículo pretende ser una introducción al estudio de la economía social brindando un primer acercamiento a las principales corrientes, enfoques y debates que, en muchos casos, se superponen, lo cual muestra la complejidad y, por ende, el desafío, que implica esta área de estudio, de investigación o de participación social y política. Partiendo de este acercamiento general, se intentará reflexionar en torno a cuál es el potencial de la economía social, cómo es posible su abordaje y cuáles pueden ser los caminos que recorra en el futuro. Para ello, se presentarán las corrientes de pensamiento que le dieron origen, se realizará una caracterización del campo a partir de la delimitación de los diversos enfoques, las particularidades de los sujetos sociales que conforman la economía social y sus diferencias con otras corrientes, los diferentes contextos territoriales. Asimismo, se analizan los cambios que ha sufrido en relación con la "cuestión social" para llegar a su situación actual. Se presentan algunos de los ejes analíticos y principales debates entendiendo al campo de la economía social como una articulación de diferencias que conforma un todo.

Por ello, en este artículo se utiliza la expresión de campo de la economía social, pues se la concibe como un área de integración. Es entendida como una rama del conocimiento específico y de investigación que posee su propio objeto de estudio, su corpus teórico y una metodología de investigación particular, pero también es concebida como una realidad social y política compleja que está constituida por experiencias, 
prácticas y actores de diferente tipo (Estado, organizaciones, productores, cooperativas, entre otros) que cada día se manifiestan, cambian y se superponen en los diferentes territorios. Por lo señalado, con campo se hace referencia a ese corpus teórico-metodológico y empírico que fue constituido y desarrollado en el transcurso del tiempo y que se encuentra en continuo cambio.

\section{Orígenes: "la cuestión social"}

La Revolución industrial marca un punto de inflexión en la historia de la humanidad por la magnitud de cambios generados por la transformación estructural dada a nivel económico y social. Se experimentó el paso de una economía rural y manual, basada en la agricultura y el comercio, a una economía urbana, industrializada y mecanizada. Esto trajo aparejadas modificaciones en la organización del trabajo. Se pasó de un ritmo natural, regido por la naturaleza y las estaciones del año, a la forma fabril, en la que los tiempos y controles eran establecidos por un patrón. Con esta forma de organización se experimentó el traslado de la población del campo a las incipientes ciudades (éxodo rural). Este proceso también fue influenciado por el cercamiento de los campos comunales y la consecuente instauración de la propiedad privada. En este escenario se evidenció la aparición de nuevas clases sociales, es decir, la división entre los trabajadores industriales (proletariado) y los dueños de los medios de producción (burguesía). Estas transformaciones radicales en los estilos de vida de la población generaron graves consecuencias sociales, como el aumento de la población en los suburbios y el despoblamiento de los campos, lo que significó la ruptura de los lazos comunitarios, así como la generación de enfermedades por la falta de higiene, de desagües y de cloacas en las ciudades. Además, a causa del poco espacio habitable y de la necesidad de compartir cuartos por los altos costos, el hacinamiento era constante. En este contexto, se registró el aumento de la pobreza y del desempleo, junto con el del trabajo forzado de niños y mujeres. Estos nuevos fenómenos de la época revelaban un problema en la organización social que fue denominado "cuestión social" (Andrenacci, 2002).

"Cuestión social" es una expresión introducida a fines del siglo xix que se refería a las condiciones en las cuales estaban viviendo las poblaciones en el marco de la Revolución industrial. Era la cuestión del pauperismo la que amenazaba el orden político y moral conocido hasta el momento. Este peligro estaba dado por la presión de todos los que no encontraban un lugar de pertenencia en esta nueva organización del trabajo y de las formas de vida. Según Castel (2006), en este contexto se "pone en cuestión" al conjunto, dado que se pregunta por la capacidad de una sociedad para mantener su cohesión, es decir, para existir como un conjunto vinculado por relaciones de interdependencia. La "cuestión social" es entendida como:

Una aporía fundamental en la cual una sociedad experimenta el enigma de su cohesión y trata de conjurar el riesgo de su fractura. Es un desafío que interroga, pone de nuevo en cuestión la capacidad de una sociedad (lo que en términos políticos se denomina una nación) para existir como un conjunto vinculado por relaciones de interdependencia (Castel, 2006, p. 20).

Como se puede observar, la "cuestión social" se plantea para los márgenes de la vida social pero pone en cuestión al conjunto de la sociedad. Siguiendo estas ideas, para Rosanvallon (1995), la "cuestión social" remitía a los cambios acontecidos por la consolidación de la organización social capitalista y la incipiente sociedad industrial. La problemática se centraba en las transformaciones de los modos de vida del proletariado en este nuevo tipo de organización social.

En este contexto, sobrevolaba la necesidad de hacer frente a "lo social": restaurar o establecer nuevos vínculos por fuera de los netamente económicos. Estas acuciantes problemáticas generaron una diversidad de protestas populares ${ }^{2}$ y el surgimiento de nuevas ideologías que demandaban mejores condiciones de vida para los trabajadores, como el socialismo, el anarquismo y el comunismo. En este escenario se desarrolló un duro debate académico en el seno del pensamiento económico sobre los valores,

1 Castel (2006) señala una diferenciación entre la noción de cuestión social y la existencia de "problemas sociales" particulares que hay que abordar uno por uno. El autor discute la pretensión de dividir los problemas para abordarlos en diferentes partes. En este sentido, frente a la crítica que realiza Castel, es posible advertir la dimensión que cobra la "cuestión social" como un todo más abarcador que debe ser abordado y no solo como la conjunción de problemas o dificultades que pueden ser resueltas de manera diferenciada.

2 La situación social a la cual se enfrentaban los trabajadores proletarios no fue aceptada de un modo pasivo, por el contrario, "el siglo xix será testigo del creciente despliegue de las luchas obreras por el aumento de salarios, la limitación de la jornada laboral y el mejoramiento de las condiciones de trabajo, así como el surgimiento de formas de organización específicas para la puesta en marcha y dirección de esas luchas" (De Ipola, 1998, p. 54). 
la política, la religión, etcétera. En tal debate el ganador fue el pensamiento económico hegemónico, lo que dejó a la economía social en un plano secundario (Chaves, 1997). Los defensores de estas posturas promulgaban el rechazo a la separación entre economía y política, tal como lo proponía la corriente principal. Estaban sensibilizados a las consecuencias que traía la Revolución industrial, el costo humano del capitalismo y promulgaban la necesidad de hacer propuestas y no mantener una postura ajena y distante frente a la acuciante realidad social.

\section{Los utópicos fundadores}

Frente a estos impactos sociales, un grupo de intelectuales y pensadores buscó un modelo económico diferente. Proponían la creación de un sistema más justo que se diferenciara de lo las instituciones y prácticas generadas por el capitalismo, como la propiedad privada y la explotación de los trabajadores. Este grupo fue denominado por Engels como socialistas utópicos. Los "utópicos" y sus ideas darían origen al socialismo con el planteamiento de un orden social de tipo ideal.

Uno de los principales exponentes del socialismo utópico fue Robert Owen (1771-1858), pensador y activista del primer socialismo británico. Fue reconocido por el impulso que logró darle al sistema cooperativo como forma alternativa al capitalismo. Proponía organizar comunidades agrícolas regidas por la lógica cooperativista de producción y de distribución. Las "granjas cooperativas" funcionaban como paliativo al desempleo, pero servían fundamentalmente como instrumento de mejoría social, ya que brindaban elementos para educar a sus integrantes con una moral adecuada. Owen llevó a cabo en su propia fábrica textil, en Escocia, transformaciones muy novedosas para la época. Entre ellas, podemos mencionar: la subida de salarios, la construcción de viviendas de buena calidad para los trabajadores, el ofrecimiento de educación para los hijos de los trabajadores, la creación de protecciones sociales vinculadas al mutualismo, entre otras.

Marx, en un manifiesto de 1864, reconoce la importancia de las "fábricas cooperativas creadas por algunos obreros audaces" (Marx, 2001). Además, agrega que esto se logró de la mano de Robert Owen, quien sembró las semillas del sistema cooperativo. El cooperativismo fue analizado por Marx desde "una triple perspectiva: a) el cooperativismo como fuerza de transformación de la sociedad capitalista en una sociedad socialista, b) el significado del cooperativismo como prefiguración de la nueva sociedad socialista y c) la actitud recomendable del cooperativismo ante el Estado" (Monzón-Campos, 2003, p. 48). En muchos pasajes de sus trabajos, Marx valoraba el cooperativismo, pues entendía que este podría ser un instrumento para la transformación social. Igualmente, siguiendo a Monzón-Campos (2003), podemos afirmar que Marx sostenía que, para superar el capitalismo, era necesario ir más allá de él; no era viable un cambio a pequeña escala y en niveles empresariales como en las cooperativas de producción. De este modo, Marx señala que las fábricas cooperativas, si no involucran un cambio más global, podrían ser utilizadas para "otros" fines.

Uno de los principales cuestionamientos hecho a los socialistas utópicos fue que su propuesta de un "orden social perfecto" no era factible en las condiciones concretas en las que se vivía. Así, Engels (2000) sostenía que "estos nuevos sistemas sociales nacían condenados a moverse en el reino de la utopía; cuanto más detallados y minuciosos fueran, más tenían que degenerar en puras fantasías". Además, afirmaba que este grupo no había logrado plantear un esquema formal y objetivo de cómo lograr una sociedad más justa, como sí lo hacían las propuestas desarrolladas por él y Marx de la mano del "socialismo científico"3. Más allá de estos cuestionamientos, los socialistas utópicos son recordados como los padres fundadores del cooperativismo y reconocidos por su análisis crítico de la evolución de la economía capitalista. Muchos de sus planteamientos y propuestas siguen vigentes en la actualidad.

Continuando con las ideas de Owen, se creó una cooperativa de consumo denominada los "Pioneros de Rochdale". Esta fue constituida por un grupo de 28 trabajadores de la industria textil descontentos con el desamparo que atravesaban los trabajadores en 1844 en Inglaterra. La tienda de la Rochdale Society Cooperative vendía productos de alimentación básicos como azúcar, harina, sal y mantequilla. La sociedad compraba al por mayor y vendía a precios bajos a sus socios. Esta cooperativa tiene una importancia

\footnotetext{
3 Término acuñado por Engels para separarse de las otras corrientes socialistas de la época. Su referente más importante fue el filósofo alemán Karl Marx. Una de las diferencias con los "utópicos" fue el desarrollo de un método científico para generar la transformación de la sociedad regida por la lucha de clases. De este modo, Engels, en su escrito "Del socialismo utópico al socialismo científico", sostiene que para convertir el socialismo en una ciencia, era indispensable, ante todo, situarlo en el terreno de la realidad.
} 
central por ser la creadora del primer estatuto de las cooperativas modernas. Los principios que establecían eran: 1 . Libre ingreso y libre retiro; 2 . Control democrático (toma de decisiones en asambleas); 3. Neutralidad política, racial y religiosa; 4 . Ventas al contado; 5 . Devolución de excedentes a los asociados; 6. Interés limitado sobre el capital (se tiene en cuenta la participación personal y no el tamaño accionario); y 7. Educación continua de los trabajadores ${ }^{4}$.

Los "pioneros" dejaron su impronta en la Argentina a partir del "Hogar Obrero". Esta fue una cooperativa de consumo y vivienda fundada en 1905 a partir de los principios del socialismo. Vale la pena mencionar a esta cooperativa dado que creó el modelo cooperativo argentino, dejando los cimientos del cooperativismo en el país ${ }^{5}$ al postular las características que debían tener las cooperativas (reglamentación, administración, principales lineamientos, etcétera). Uno de sus propósitos era proporcionar crédito a sus socios para adquirir viviendas y comprar terrenos para edificar, o bien edificarlos para obtener renta y así prestar dinero a sus socios y diferenciarse de la empresa capitalista, pues querían defender los ingresos de los socios y no agregar ganancias al capital. Eran críticos de la actividad inmobiliaria capitalista que no atendía a la carencia habitacional de los trabajadores.

\section{Enfoques de la economía social}

Estas primeras experiencias en torno a la economía social fueron clasificadas por Caracciolo y Foti (2012) como parte de una vertiente denominada "histórica tradicional" vinculada a lo institucional, como, por ejemplo, el mutualismo y el cooperativismo. Esta corriente se ubica a fines del siglo xviii y principios del xix en Europa. En Argentina y América Latina, llega de la mano de los inmigrantes europeos vinculados a las ideas socialistas y anarquistas presentes en esas latitudes. Dentro de esta vertiente - definida como de primera generación-, las autoras también incorporan otra modalidad menos formal: la agricultura

\footnotetext{
4 En este periodo, se comienza a hablar de "movimiento coop erativo" en un intento por homogeneizar teóricamente el cooperativismo. Asimismo, se establece una dimensión política de las cooperativas, vinculada a la transformación social (Monzón-Campos, 2003, p. 13)

5 Argentina posee una fuerte tradición de organizaciones cooperativas, gremios, asociaciones y mutuales gracias a la llegada de inmigrantes y sus ideas a fines del siglo xix.
}

familiar y campesina junto. Igualmente, incluyen a los pequeños productores, las comunidades aborígenes y los cuentapropistas urbanos de diferentes rubros (pequeños comerciantes, artesanos, talleristas, entre otros). Como segunda, y más reciente, vertiente identifican los emprendimientos familiares y asociativos generados por necesidad o por convicciones valorativas que buscan crear otra sociedad con una lógica diferente a la del mercado. Las cooperativas de trabajo, las empresas recuperadas, los emprendimientos productivos alimentarios y textiles, entre otros, conforman esta vertiente.

Estas experiencias no solo pueden ser clasificadas temporalmente, sino que también es posible identificar enfoques desde los que son, generalmente, conceptualizadas. Así, según Hintze (2010) son vistas como: 1. "Políticas pobres para pobres", dado que constituyen una forma más de apoyo a sectores vulnerables excluidos del mercado de trabajo en el marco de políticas sociales asistenciales; 2 . Organizaciones socioeconómicas que generan trabajo, pero que no tienen la posibilidad de evitar la subsunción al capital al cual terminan sirviendo por disminuir la presión sobre el mercado de trabajo; 3 . Experiencias que poseen un potencial emancipatorio y contra-hegemónico, que posibilitan la construcción de una nueva cultura que dispute espacios al capitalismo (concepción compartida por Hintze). Como se puede observar, estas posturas pueden resultar contrapuestas, si tenemos en cuenta que algunas perciben un potencial en la economía social para disputarle espacios al capitalismo y otras la consideran meramente como un paliativo de este mismo sistema que no da la posibilidad de generar una transformación social. Esto es un ejemplo de la heterogeneidad y diversidad de posturas señaladas en la introducción de este artículo. Estas concepciones son parte de las "miradas externas" a este campo, pero también son compartidas por estudiosos, miembros de organizaciones, funcionarios y sujetos que forman parte del ámbito de la economía social.

Asimismo, dada su diversidad y complejidad, es posible identificar una división en tres planos cognitivos de este campo. Según Chaves (1997), la economía social: a) es una realidad social diferente a la de la economía dominante que constituye una vía de acción y expresión de cada sociedad; también es b) una disciplina científica que estudia aquella realidad, es una ciencia cuyo objeto de estudio difiere del que ha tenido la hegemonía en la ciencia económica (el objeto es institucional); y por ende, c) posee 
un enfoque metodológico alternativo. Dentro de lo planteado por Chaves (1997), es posible hallar un paradigma de investigación que, desde una perspectiva compleja, holística e interdisciplinaria, permita entender la particularidad de esta realidad social multidimensional. En este sentido, plantea crear una nueva ética del investigador-profesional que explicite el sistema de valores que orienta sus análisis. Esta es una crítica que el autor realiza a la supuesta objetividad o neutralidad que postula la corriente principal de la economía tradicional.

En este sentido, como se señaló anteriormente, para designar a la disciplina, realidad social y método que comprende la economía social, se ha construido la categoría analítica de campo. De este modo, se integran estos tres ejes, señalados por Chaves (1997), en un concepto global que intenta mostrar que la economía social posee su propio corpus teórico, tiene una metodología particular para ser abordada y que, además, conforma una realidad social en la cual se trabaja, se produce, se gestan organizaciones, se participa y debate políticamente, se realizan propuestas, se aprende y enseña, etcétera. En definitiva, una realidad efervescente y en continuo cambio.

\section{Los contextos territoriales y sus diferencias}

Si bien el origen de la economía social se da, a partir de lo planteado y desarrollado, en los países centrales (especialmente europeos), con los años y las diversas experiencias comenzaron a cristalizarse las diferencias con los países periféricos ${ }^{6}$. De este modo, se podría decir que es posible encontrar dos perspectivas

\footnotetext{
6 Las expresiones "países centrales" y "países periféricos" se asocian a la escuela de pensamiento de la cepal y, específicamente, al pensador Raúl Prebisch. En esta institución, la oposición entre "periferia" y "centro" desempeñó un papel central en el análisis de las tendencias económicas y sociales latinoamericanas y su particularidad frente a los países desarrollados. Específicamente, se la utilizó "para afirmar que la estructura mencionada determinaba un patrón específico de inserción en la economía mundial [...] la estructura socioeconómica periférica determina un modo singular de industrializar, introducir el progreso técnico y crecer, así como un modo peculiar de absorber la fuerza de trabajo y distribuir el ingreso. 0 sea, en sus características centrales, los procesos de crecimiento, empleo y distribución del ingreso en la periferia serían distintos de los que ocurren en los países centrales. Las diferencias deben hallarse en el hecho de que las economías periféricas poseen una estructura poco diversificada y tecnológicamente heterogénea, que contrasta con el cuadro observado en los países centrales" (Bielschowsky, s. f.)
}

situadas en realidades históricas, culturales, políticas y sociales diferentes.

Según Mutuberría-Lazarini (2008), desde la periferia, la Economía Social es entendida de un modo más radical. En estas latitudes se sostiene que el sistema capitalista vigente destruye las bases de la vida de los seres humanos, dado que se da prioridad a la racionalidad instrumental sobre la reproducción de la vida. Según esta perspectiva, se sostiene que el de la economía social es un sector especial de la economía cuyas actividades son motivadas por la reciprocidad y la solidaridad. Igualmente, se sostiene que las prácticas existentes son heterogéneas porque parten de diferentes situaciones y problemas cercanos a cada realidad (Mutuberría-Lazarini, 2008). Por esta razón, son prácticas muy variadas y no se limitan solo a las cooperativas, asociaciones y mutuales, como sí sucede en los países centrales, en los cuales la economía social es definida de forma negativa (se dice que no es parte ni de lo público ni de lo privado tradicional). En los países centrales, la economía social es concebida como un tercer sector que existe dentro del sistema capitalista pero con "otra" lógica para la resolución de los problemas presentes en la empresa capitalista. De este modo, afirman que no es una economía independiente de la capitalista (Chaves, 1997), sino que está centrada en la perspectiva institucional organizativa (cooperativas, asociaciones, fundaciones y mutuales). La perspectiva económica que asumen es la "entendida desde su sentido más clásico: asignación de recursos limitados para fines múltiples, por medio de la producción, distribución y consumo de bienes y servicios" (Mutuberría-Lazarini, 2008, p. 2).

Por su parte, marcando amplias diferencias, la perspectiva de los países periféricos se basa en la propuesta de nuevas formas de organización del trabajo: la unidad de quienes poseen y usan los medios de producción y distribución; el principio de la socialización de estos medios; la reproducción de la vida, el enfoque en el trabajo y las condiciones en las que se desarrolla; la posesión colectiva de los medios de producción por los sujetos que los utilizan para producir y la participación directa de los trabajadores (Mutuberría-Lazarini, 2008).

\section{La cuestión del sujeto como diferencia}

Dentro de las diferencias encontramos también la identificación de los sujetos. En términos generales, existe una identificación del comportamiento humano con las concepciones del Homo œconomicus. 
Este concepto, utilizado por la escuela neoclásica de economía, sostiene que los sujetos en general se comportan de manera individualista, competitiva e indiferente hacia los otros. Así, el ser humano es entendido como racional, capaz de decidir y actuar con el objetivo principal de obtener la maximización de sus beneficios. Esta representación teórica forma parte de los conceptos dominantes del sistema capitalista y postula que este es un comportamiento universal y a-histórico, por ende, "igual en todas las épocas y lugares".

Esta corriente de pensamiento fue $-\mathrm{y}$ es - altamente cuestionada desde diversas perspectivas. Una de ellas sostiene que, así identificado, este sujeto posee demasiada comprensión de macroeconomía, tiene una gran previsión económica y cuenta con mucha información previa para tomar decisiones, por lo cual no respondería al "común" de la población. Estudios de la antropología económica (han demostrado que en las sociedades tradicionales la producción e intercambio de bienes siguen patrones de reciprocidad y cooperación ${ }^{7}$. Otros estudios antropológicos y psicológicos también señalan que el ser humano tiene una capacidad para "relacionarse con otros" y actuar de un modo intersubjetivo (Caracciolo y Foti, 2012). Esto es lo que le ha permitido sobrevivir a lo largo de la historia. Desde la sociología se critica el concepto de Homo œconomicus porque deja a un lado gustos, preferencias, pertenencias sociales, acceso a la educación, entre otros intereses de los sujetos. Los estudios realizados en esta disciplina sostienen que los sujetos no son independientes de los condicionamientos sociales a la hora de actuar.

Desde la perspectiva de los países periféricos se retoma una visión antropológica del sujeto. Se afirma que no existe una forma única y universal de actuar. Igualmente, se sostiene que los sujetos tienen "necesidades antropológicas" que se vinculan con la satisfacción de necesidades materiales y fisiológicas, pero también con las afectivas y espirituales (Hinkelammert y Mora-Jiménez, 2008). Los sujetos establecen relaciones de reciprocidad y comunitarias. Se espera que el sujeto perteneciente al campo de la economía social contribuya a la reproducción

"Polanyi (2003) apoyado en estudios etnológicos de otros investigadores, mostró que la motivación de la ganancia no es algo natural, y no recoge lo que ocurría en las economías antiguas. Esta orientación ha venido a ser más importante sólo en los últimos siglos, con el capitalismo y la economía de mercado, que es una institución que favorece y empuja a una acción económica motivada por la ganancia” (González-Meyer, 2012, p. 210). ampliada de la vida de todos, es decir, al "bien vivir individual, comunitario y social" (Arruda, 2004, p. 378), a partir del vínculo con otros y con la naturaleza, pues el ser humano es entendido también como parte de la naturaleza.

Desde una perspectiva de tipo política se sostiene que está emergiendo, de los propios procesos, un nuevo sujeto - perteneciente al campo de la economía social- que actúa de manera consciente en relaciones económicas alternativas y que se propone alcanzar un orden económico social diferente (Rincón-Gamba, 2012). Se entiende, entonces, como un sujeto político y económico comprometido con su realidad. Es un sujeto activo que participa a partir del vínculo que establece con otros sujetos y con los lugares en donde trabaja y habita. En definitiva, es un sujeto que está vinculado con las dinámicas propias de cada territorio. En el territorio es en donde se inscriben sus prácticas, sus relaciones con el Estado y con el capital de un modo particular (Rincón-Gamba, 2012). De este modo, el anclaje territorial, a la hora de pensar el desarrollo y la consolidación de las iniciativas de la economía social, resulta sumamente relevante, pues cada territorio y contexto le pone a esta su impronta - como lo señala la clasificación de países periféricos y centrales dada por Mutuberría Lazarini. Cada territorio posee sus problemáticas, tensiones intrínsecas y también sus formas de solidaridad. Es así que en el territorio aparecen las disputas con las cuales los sujetos lidian cotidianamente. Por ello, desde su propia realidad territorial, despliegan diversidad de acciones y estrategias para la reproducción de la vida. En esta realidad efervescente y compleja es que se cristaliza lo conflictivo y lo contradictorio que generalmente las conceptualizaciones teóricas no muestran a simple vista.

\section{El devenir de un campo}

Como se ha dicho, el anclaje territorial resulta relevante para comprender la diversidad que asume el campo de la economía social en diferentes contextos, pero también se requiere, para comprender su complejidad, dar cuenta de los cambios que atravesó a lo largo del tiempo desde su origen como propuesta alternativa al capitalismo. Siguiendo a Chaves (1997), es posible observar que a fines del siglo xix el significado del término "economía social" se transforma profundamente. Deja su rol como crítico del modelo existente para centrarse en el estudio de cierto tipo de actividades y de actores que se escapan de la lógica 
dominante. Su objeto de estudio se circunscribió a las formas institucionales basadas en la libre asociación. Según el autor, este cambio no implicó que la economía social se marchitara, pues como enfoque continuó existiendo dentro del pensamiento económico. Hacia 1930, según Mutuberría-Lazarini (2008), como área de discusión académica reduce su desarrollo en un contexto de avance del fordismo y la aparición del Estado de bienestar. A partir de los años setenta, re-emerge el concepto de economía social y se amplía su marco social de referencia para centrarse de nuevo en las formas que cuestionan al sistema capitalista.

Esto se vincula con la aparición, a mediados de la década de los setenta, de un nuevo escenario político y económico. Desde ese momento el mundo ha sufrido grandes transformaciones, principalmente vinculadas al desmoronamiento de la sociedad salarial. A partir de este momento, Gran Bretaña y Estados Unidos adoptaron una nueva política económica denominada neoliberalismo ${ }^{8}$. Esta corriente fue impulsada fuertemente por economistas ortodoxos, quienes influenciaron al poder político desde la academia y la empresa. Es una versión actualizada del liberalismo originario que fue aplicado por casi todos los países capitalistas del mundo. Condujo, desde los nuevos postulados, ${ }^{9}$ al abandono de las políticas intervencionistas que, hasta el momento, habían sido implementadas en el marco del Estado de bienestar, instaurado en los países capitalistas más desarrollados desde 1930.

Es de destacar la aparición de nuevos discursos, políticas e instituciones, propuestas tanto desde el campo académico como desde el político, que permitieron legitimar estas acciones en lo que se denominó pensamiento único, es decir, natural y sin otra alternativa posible. De este modo, se presentan las premisas neoliberales como una suerte de destino inevitable (Bologna-Salvat, 2012). Otra de las

\footnotetext{
8 "El neoliberalismo es una teoría de prácticas políticas económicas que proponen que el bienestar humano puede ser logrado mejor mediante la maximización de las libertades empresariales dentro de un marco institucional caracterizado por derechos de propiedad privada, libertad individual, mercados sin trabas, y libre comercio. El papel del Estado es crear y preservar un marco institucional apropiado para tales prácticas" (Harvey, 2008).

9 Dentro de este nuevo esquema político, económico y social, las principales acciones desarrolladas buscan acabar con las barreras al ingreso de mercancías y capitales, la supresión de políticas de promoción de la industria, los controles por parte de organismos internacionales de crédito, las privatizaciones, la ejecución de políticas sociales focalizadas, entre otros.
}

particularidades de esta corriente de pensamiento es "la creencia en el mercado puesto como institución, mecanismo, orden espontáneo clave para la realización de la libertad de cada quien y de la totalidad. El mercado les aparece como el mejor modo de asignar recursos escasos" (Bologna-Salvat, 2012, p. 91).

Con estas medidas, las problemáticas sociales se profundizaron en las décadas del ochenta y del noventa. Según De Ipola (1998), desde fines del segundo milenio se asiste nuevamente a una "erosión progresiva y acelerada de los dispositivos que aseguran el lazo social" (p. 52). Se ha hecho patente el derrumbe de la sociedad conocida hasta el momento. El desmoronamiento de la sociedad salarial implicó un cambio en el mundo del trabajo con las nuevas formas que adoptó el empleo: subempleo, trabajadores sin trabajo, falta de capacitación para los nuevos empleos, erosión de las organizaciones colectivas de trabajo, devaluación de títulos, tercerización, etcétera; todo en un marco de alto desempleo.

En este contexto, se vuelve a poner en tensión la capacidad de una sociedad para mantenerse unida frente al aumento de la desocupación y la aparición de nuevas formas de pobreza. En este panorama retornan los interrogantes sobre cómo lograr la integración social, qué caminos posibles se pueden recorrer. Qué hacer frente a la "cuestión social" era, nuevamente, la pregunta a responder. Aquí se puede advertir cierta diversidad de posturas entre algunos de los autores ya clásicos sobre esta temática. Para Rosanvallon (1995), es necesario hablar de la "nueva cuestión social", dado que no se trata de una simple vuelta a los problemas del pasado, pues los nuevos fenómenos de exclusión y pobreza no pueden ser interpretados con las antiguas categorías de explotación. Por su parte, para Castel (2006), es necesario interpretar estas transformaciones de la realidad social como una metamorfosis, ya que se reeditan los problemas del pasado que ponen en tensión al conjunto de la sociedad. De este modo, "no se estaría en presencia de una nueva cuestión social, sino de una metamorfosis del tradicional problema de cohesión social que se deriva de las formas de organización entre capital y trabajo propias del capitalismo moderno" (Lo Vuolo, Barbeito, Fataussi y Rodríguez, 2004, p. 211). Más allá de estas diferencias, ambos coinciden en la relevancia de esta problemática e identifican un cambio de época. Según Rosanvallon (1995), se ingresa en una nueva era de lo social y lo político.

En este contexto, se gestó la aparición de nuevos actores sociales, demandas y formas de organización 
y acción (manifestaciones y protestas sociales, cortes de ruta, clubes de trueque, asambleas vecinales, empresas recuperadas, etcétera). Estas son concebidas como nuevas formas de reclamo frente a la coyuntura. En este escenario, es posible advertir la revivificación de las experiencias de la economía social en tanto formas de resistencia a la exclusión social imperante (resultado los efectos generados por las políticas neoliberales implementadas). Desde la década del ochenta, la noción de economía social comienza a ser cada vez más reconocida y utilizada académicamente, e incluso por las autoridades públicas (Defourny, 2014). Por iniciativa de la Unión Europea se la reconoce como una forma de combatir la desocupación y promover nuevos empleos. También comienza a ser utilizada por las Naciones Unidas y la Organización Internacional del Trabajo (oit). Para MonzónCampos (2003, p. 27):

la crisis de confianza y la incapacidad de esas instituciones tradicionales para dar respuesta adecuada a los nuevos retos de la economía globalizada están en la base del notable crecimiento de las investigaciones orientadas al nuevo papel que las cooperativas y la economía social puede desempeñar en la consolidación de la sociedad del bienestar.

\section{La economía social como protagonista}

Como se pudo observar, la economía social surge en un momento histórico en el cual hay una crisis profunda de integración social denominada "cuestión social" y vuelve a tener relevancia en el contexto de la "nueva cuestión social" como una propuesta superadora del actual sistema. En el caso Europeo, es posible detectar el reavivamiento de las corrientes y prácticas de la economía social a partir de la crisis del $2008^{10}$. En este contexto, estas experiencias son

10 Para Rapoport y Brenta (2010, p. 9), "el término crisis referencia en una economía de mercado a la cuestión de los ciclos o fluctuaciones económicas. No son factores externos al sistema, como los desastres climáticos o las guerras, los que originan las crisis, aunque pueden coadyuvar a ellas, sino elementos endógenos al mismo. En particular, lo que caracteriza el periodo de contracción o recesión, cuya fase más aguda llamamos crisis, es la disminución general de la actividad económica, reflejada en la baja de la producción de bienes y servicios y del empleo, acompañada por una reducción general del nivel de beneficios, precios y salarios". Específicamente, la crisis europea, denominada también "crisis de la Deuda Europea; Crisis Financiera de la Eurozona; o Crisis de la Deuda Soberana de la Eurozona, más bien debiera considerarse como continuación de la crisis del capitalismo que inició en Esta- posicionadas como opciones de salida frente a la crisis. Esto no significa que no haya habido acciones de este estilo en décadas pasadas, sino que estas encontraron otro escenario y nuevos actores participando y dándole estatus a la economía social como respuesta a la nueva coyuntura. De este modo, es posible observar el cuestionamiento al sistema vigente y la puesta en práctica de acciones ligadas al campo de la economía social. Es notable el resurgimiento y desarrollo de cooperativas y empresas recuperadas en diferentes países europeos, especialmente en Italia, España y Grecia, países fuertemente castigados por la crisis social, política y económica ${ }^{11}$.

Es posible pensar, a la luz de este resurgimiento, que la economía social retoma su preponderancia, pues se presenta como una posibilidad siempre presente por su capacidad de reproducción en diferentes contextos históricos e institucionales. En este sentido, muestra su dinamismo y flexibilidad. Asimismo, retorna como centro de análisis y acción porque tiene en cuenta la realidad particular de cada contexto territorial (contradictorio, conflictivo, afectivo) y la multiplicidad de sujetos sociales que la componen (heterogeneidad). Además, se convierte en una alternativa dado que se basa en una ética diferente a la hegemónica y porque es una posibilidad de los dominados-explotados, junto a otros, para lograr un cambio. En los contextos de crisis de integración se "vuelve" a la comunidad como constitutiva del ser ya que "no hubo, no hay y no puede haber individuos fuera de la comunidad" (Coraggio, 2009, p. 4).

Siguiendo esta línea, se reconoce la necesidad de incorporar en la descripción de este campo la noción de solidaridad. La economía social y solidaria, "hace referencia a las relaciones en donde la justicia y la equidad constituyen valores y prácticas centrales que orientan las actividades económicas" (Caracciolo y Foti, 2012, p. 2). Para las autoras, "[la economía social] es solidaria cuando a las formas no capitalistas

dos Unidos en el año 2007" (Blas-Ruiz, 2013, p. 1). Principalmente, "la crisis generó ante todo el derrumbe de los principales bancos de inversión, así como de numerosas entidades financieras en ee.uu. y en Europa, donde ocurrieron booms inmobiliarios similares" (Rapoport y Brenta, 2010, p. 20).

11 Para ampliar pueden consultarse la nota periodística del diario La Nación (13 de mayo de 2012), "De la indignación a la acción", disponible en: http://www.lanacion.com.ar/1472450-de-la-indignacion-a-la-accion; y la nota periodística del diario Página 12 (3 de marzo de 2013), "Experiencia argentina. Recuperadas griegas", disponible en: http://www.pagina12.com.ar/diario/suplementos/ cash/17-6658-2013-03-03.html 
de trabajo se suman prácticas orientadas a la ética del bien común, la justicia, la equidad y el cuidado del planeta entre los distintos actores y en los ámbitos en los que se desempeñan" (Caracciolo y Foti, 2012, p. 16). De Melo Lisboa (2004) afirma que el valor ético sobre el cual se sostiene la economía social es la solidaridad, pero aclara que esta no surge de un modo espontáneo. Por ello, es necesario generar valores que se desarrollen culturalmente, pues ella es una construcción social que varía en el tiempo y en el espacio. En este sentido, sostiene que hay que superar la solidaridad de sobrevivencia, es decir, la que surge en los tiempos de crisis o la que se genera como mecanismo de cooperación para mejorar las condiciones entre miembros de una misma clase. Afirma que es necesario generar una solidaridad con el distinto, con el diferente, a través de la empatía y la compasión. Hace referencia una solidaridad de tipo política. De este modo, "es necesario un trabajo cultural para que emerja la solidaridad consciente. Y esta no se realiza como un estado o punto de llegada, sino que es un desafío y una elección del sujeto en cada momento y en cada acto de su existencia” (Arruda, 2014, p. 374).

\section{Reflexiones finales}

Desde su origen, a través de las propuestas de los socialistas utópicos, las experiencias de economía social forman parte del entramado social, aunque su visibilidad cambie por momentos. Esto se evidencia especialmente en períodos en los que el orden social conocido entra en tensión y se producen profundos cambios sociales. Es posible observar, de este modo, que el campo de la economía social cobra más relevancia - o no- dependiendo del momento histórico. En cada nueva "aparición", o nueva "ola" de entidades de economía social, regresan los cuestionamientos más generales al sistema y, por ende, la posibilidad de llevar a cabo una transformación de lo existente (Chaves, 1997). Renacen las oportunidades tanto teóricas como empíricas para proponer un cambio.

En la actualidad, se está atravesando un periodo de transición en el cual hay una disputa por los sentidos y las interpretaciones de la realidad. El mundo se enfrenta a una incertidumbre que parece no tener un claro horizonte. Para De Melo-Lisboa (2004), vivimos en un tiempo de transición en el que es posible encontrar variadas opciones; la cuestión, nos dice, es saber cuál elegir.
Estos tiempos pueden ser propicios para crear un lazo social que respete las diferencias culturales, territoriales y sociales, pero que articule a los seres humanos como un todo en el que la pertenencia social se ancle fuertemente en la ciudadanía. Una propuesta posible es la profundización de la economía social como un campo desde el cual pensar otras formas de integración social. Puede ser el espacio para resignificar la pertenencia por fuera de los cánones conocidos, que generalmente están vinculados al mundo del trabajo. Para lograrlo, no solo se debe involucrar a los sujetos, sino que también se debe repensar al Estado, para que sea un impulsor y promotor, y a la academia, para que asuma un lugar más comprometido en la generación de pensamiento crítico junto a los diversos sujetos y organizaciones sociales, gestores clave de los procesos de construcción de otra sociedad.

Esto resulta ser un gran desafío porque requiere liberarse del modo eurocéntrico de producción del conocimiento, y de implementación de políticas, y profundizar en categorías analíticas propias que tengan en cuenta la multiplicidad de modalidades que asume la economía social en la actualidad (cooperativas de vivienda y de trabajo, movimientos campesinos, emprendimientos familiares y asociativos, empresas recuperadas, organizaciones feministas, ecologistas, comunidades aborígenes, etcétera), los contextos históricos y geográficos en los que se inserta, y que recuperen los saberes y prácticas que construyen los pueblos en su cotidianeidad. Recientemente, Escobar (2016) señaló que, en América Latina, los análisis teórico-políticos para repensar la región reverberan a lo largo y ancho del continente; pero esta contribución no es solo de tipo académica, sino que los conocimientos de los pueblos, las comunidades y muchos movimientos sociales están en la avanzada del pensamiento para lograr transiciones. Estos conocimientos, según el autor, cobran una gran relevancia ante las graves crisis ecológicas y sociales que se enfrentan en la actualidad.

Lograr este objetivo implica un cambio más profundo vinculado con la subjetividad, es decir, con las formas en las cuales comprendemos y miramos la realidad y lo que nos rodea, pues en la actualidad:

todos somos sujetos de un orden capitalista, en el sentido en que nuestra comprensión y nuestras emociones, ambiciones personales y visiones de la posibilidad colectiva se organizan en torno a la creencia visceral en la presencia y el poder hegemónicos del 
capitalismo (Gibson-Graham, 2007, p. 15, como es citado en Rincón Gamba, 2012, p. 30).

Este periodo de transición e incertidumbre al que estamos asistiendo es propicio para pensar e impulsar acciones alternativas. Estas implican necesariamente refundar la utopía, pues:

siempre existe la necesidad de tener en mente una visión utópica, de una manera u otra, un lugar al que deseamos llegar, aunque al final no lleguemos, en cierto sentido no importa mucho si se llega o no. Si se tiene una visión, tratando de cambiar las cosas, estas se mueven en una dirección u otra (Harvey, 2013).

\section{Referencias}

Andrenacci, L. (2002). Cuestión social y política social en el Gran Buenos Aires. Buenos Aires: Ediciones Al Margen, Universidad Nacional de General Sarmiento.

Arruda, M. (2004). Socioeconomía solidaria. En A. D. Cattani (Comp.), La otra economía (pp. 373-387). Buenos Aires: Universidad Nacional de General Sarmiento, Altamira, Fundación osde.

Bielschowsky, R. (s. f.). Evolución de las ideas de la cepal. Recuperado de http://www.cepal.org/publicaciones/ xml/3/19373/bielchow.htm

Blas-Ruiz, R. (2013). Crisis europea, crisis del capitalismo: causas y efectos. Recuperado de http://buenaspracticas.stps.gob.mx/buenaspracticas/administrador/ lecturas/pdf/crisis_europea_crisis_del_capitalismo-2013.pdf

Bologna-Salvat, P. (2012). Del neoliberalismo y algunas señas de identidad. En R. González Meyer y H. Richards (Comps.), Hacia otras economías, critica al paradigma dominante (pp. 77-98). Santiago: lom Ediciones.

Castel, R. (2006). La metamorfosis de la cuestión social. Una crónica del salariado. Buenos Aires: Paidós.

Caracciolo, M. y Foti, P. (2012). Economía social y solidaria. Aportes para una visión alternativa. Programa de Estudios Avanzados en Economía Solidaria. idaes-unsam. Recuperado de http://base.socioeco.org/docs/ ess-una-vision-alternativa.pdf

Cattani, A. D. (Comp.). (2007). La otra economía. Buenos Aires: Universidad Nacional de General Sarmiento, Altamira, Fundación osde.

Chaves, R. (1997). La economía social como enfoque metodológico, como objeto de estudio y como disciplina científica. Revista ciriec-España, 33, 115-140. Recu- perado de http://www.uv.es/uidescoop/chaves-ciriec33esp.pdf

Coraggio, J. L. (2009). Territorio y economías alternativas (Ponencia presentada en el Seminario internacional: "Planificación regional para el desarrollo nacional. Visiones, desafíos y propuestas". La Paz, Bolivia, 30 a 31 de julio). Recuperado de http://www.coraggioeconomia.org/jlc_publicaciones_ep.htm

Defourny, J. (2014). La larga marcha del concepto de economía social. En M. Vuotto (Comp.), Economía social. Precisiones conceptuales y algunas experiencias históricas (pp. 143-154). Los Polvorines: Universidad Nacional de General Sarmiento.

De Ipola, E. (1998). La crisis del lazo social: Durkheim, cien años después. Buenos Aires: Eudeba.

De Melo-Lisboa, A. (2004). Solidaridad. En A. D. Cattani (Comp.), La otra economía (pp. 389-401). Buenos Aires: Universidad Nacional de General Sarmiento, Altamira, Fundación osde.

Engels, F. (2000). Del socialismo utópico al socialismo científico. Marxists Internet Archive. Recuperado de https://www.marxists.org/espanol/m-e/1880s/dsusc/1. $\mathrm{htm}$

Escobar, A. (2016). Desde abajo, por la izquierda y con la Tierra. Serie Desafíos Latinoamericanos, 7. Recuperado de http://blogs.elpais.com/contrapuntos/2016/01/ desde-abajo-por-la-izquierda-y-con-la-tierra.html

Gibson-Graham, J. K. (2007). La construcción de economías comunitarias: las mujeres y la política del lugar. En W. Harcourt y A. Escobar (Eds.), Las mujeres y las políticas del lugar (pp. 147-173). México: Universidad Nacional Autónoma de México.

Harvey, D. (2008). El neoliberalismo como destrucción creativa. Revista Realidad Económica. Pensamiento Crítico. Recuperado de http://www.iade.org.ar/modules/noticias/article.php?storyid $=2378$

Harvey, D. (2013). El neoliberalismo como "proyecto de clase". Viento Sur Info. Entrevista con David Harvey, 8 de abril. Recuperado de http://www.vientosur.info/ spip.php?article7843

Hinkelammert, F. y Mora-Jiménez, H. (2008). Reproducción de la vida, utopía y libertad: por una economía orientada hacia la vida. Otra Economía, II(2), 22-27. Recuperado de http://revistas.unisinos.br/index.php/ otraeconomia/article/view/1078/270.

Hintze, S. (2010). La política es un arma cargada de futuro. La economía social y solidaria en Brasil y Venezuela. Buenos Aires: ciccus-Clacso. 
González-Meyer, R. (2012). De la economía a la socio-economía. En R. González-Meyer y H. Richards (Comps.), Hacia otras economías, critica al paradigma dominante. Santiago: lom Ediciones.

Lo Vuolo, R., Barbeito, A., Fataussi, L. y Rodríguez, C. (2004). La pobreza... de la política contra la pobreza. Buenos Aires: ciepp-Miño y Dávila.

Marx, K. (2001). Manifiesto inaugural de la asociación internacional de los trabajadores (Publicado en el Folleto Addres and Provisional Rules of the Working Men's International Association, Londres). Marxists Internet Archive.

Monzón-Campos, J. L. (2003). El cooperativismo en la historia de la literatura económica. Revista de Economía Pública, Social y Cooperativa, ciriec-España, 44, 9-32.

Mutuberría-Lazarini, V. (2008). El debate en torno a la Economía Social: discusiones fundamentales desde la perspectiva de los países centrales y la perspectiva de los países de la periferia (Ponencia presentada en el X Encuentro Internacional de Economistas sobre Globalización y Problemas del Desarrollo. anec, La Habana, Cuba). Recuperado de http://www.tau.org.ar/upload/ 89f0c2b656ca02ff45ef61a4f2e5bf24/Ponencia__Encuentro__Cuba.pdf

Rapoport, M. y Brenta, N. (2010). La crisis económica mundial: ¿el desenlace de cuarenta años de inestabilidad? Revista Problemas del Desarrollo, 163(41), 7-30.

Rincón-Gamba, L. (2012). Territorios y sujetos de la economía social y solidaria. Otra Economía, 6(10), 24-36. Recuperado de http://www.academia.edu/2954854/ Territorios_y_sujetos_de_la_econom\%C3\%ADa_social_y_solidaria

Rosanvallon, P. (1995). La nueva cuestión social. Repensar el Estado providencia. Buenos Aires: Manantial. 